\title{
Examination of foramen tympanicum: an anatomical study using cone-beam computed tomography
}

\author{
Y. Deniz¹ , G. Geduk², A.Z. Zengin ${ }^{3}$ \\ ${ }^{1}$ Department of Oral and Maxillofacial Radiology, Samsun Oral and Dental Health Hospital, Samsun, Turkey \\ 2Department of Dental and Maxillofacial Radiology, Faculty of Dentistry, Bülent Ecevit University, Zonguldak, Turkey \\ ${ }^{3}$ Department of Dental and Maxillofacial Radiology, Faculty of Dentistry, Ondokuz Mayıs University, Samsun, Turkey
}

[Received: 19 June 2017; Accepted: 24 July 2017]

\begin{abstract}
Background: The foramen tympanicum (FT) is an osseous dehiscence of the temporal bone and usually closes by the age of 5 years. The foramen is located posteromedial to the temporomandibular joint and anteroinferior of the external auditory canal. The aim of this study is to define the prevalence, location and size of the foramen.

Materials and methods: We retrospectively examined 200 cone-beam computed tomography (CBCT) images (400 ears). We used a CBCT dental imaging system (GALILEOS, Sirona Dental Systems, Bensheim, Germany) working at 15-30 mA and $98 \mathrm{kV}$. We noted size and location (unilateral and bilateral) of the present FT. Results: Foramen tympanicum was determined in $11.5 \%$ of 200 patients (they had FT at least on one side of the head). This was bilateral in 5 (2.5\%) patients. Prevalence of the FT was significintly higher in females (8\%) than in males (3.5\%). FT was found more frequently on the left side (7.5\%) than on the right side (4\%). Mean axial diameter was $1.13 \mathrm{~mm}$ (range $0.23-4.43 \mathrm{~mm}$ ), and mean sagittal diameter was $1.44 \mathrm{~mm}$ (range 0.22-3.99 $\mathrm{mm}$ ).

Conclusions: Considering that FT was present in $11.75 \%$ of patients, radiologists and clinicians should be aware of the possible presence of this defect. It is known that this developmental dehiscence may cause herniation of temporomandibular joint, formation of salivary otorrhea, and spread of tumour or infection to the infratemporal fossa from external auditory canal. This study showed that CBCT may be preferred for imaging these conditions. (Folia Morphol 2018; 77, 2: 335-339)
\end{abstract}

Key words: foramen tympanicum, foramen of Huschke, cone-beam computed tomography (CBCT), dental volumetric tomography

\section{INTRODUCTION}

Foramen tympanicum (FT), also called as foramen of Huschke, is an anatomic variation situated in the tympanic portion of the temporal bone. It was determined first by Emil Huschke. FT occurs during the time of embryological development of the viscerocranial bone $[2,17]$. When present, it is located at the an- teroinferior of the external auditory canal (EAC) and external auditory meatus (EAM), posteromedial to the temporomandibular joint (TMJ) $[3,16]$ (Figs. 1-4).

Development of the EAC begins at 8 weeks of pregnancy. A funnel-shaped tube is formed from first branchial cleft. After 1 week, a solid epidermal lamina develops at the medial of this funnel-shaped tube.

Address for correspondence: Dr. Y. Deniz, Samsun Oral and Dental Health Hospital, Oral and Maxillofacial Radiology Department, 55100 Illkadım, Samsun, Turkey, tel: +90 (507) 3578000, e-mail: yesim.deniz@saglik.gov.tr, yesmdeniz@gmail.com 


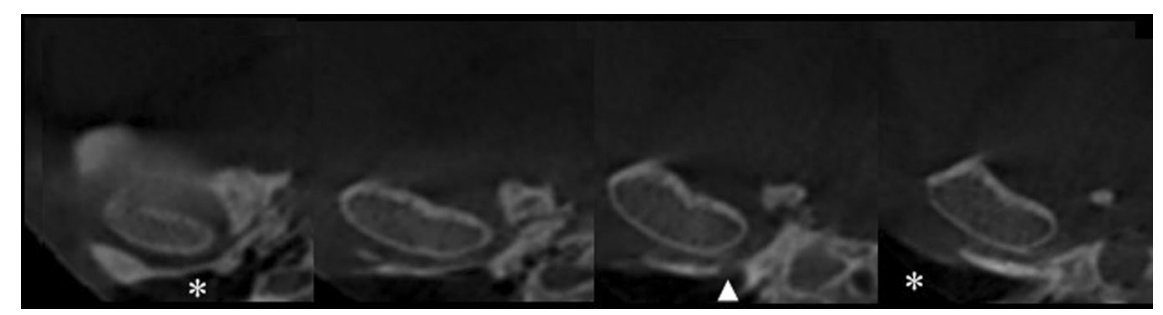

Figure 1. A cone beam computed tomography scan (coronal plane) showing the foramen tympanicum (FT) on the posteromedial aspect of right temporomandibular joint (arrowhead) adjacent to the external auditory canal (asterisk).

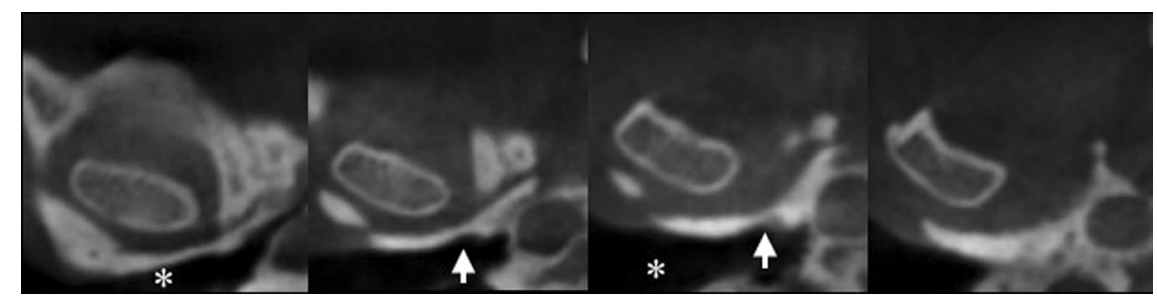

Figure 2. A cone beam computed tomography scan (coronal plane). There is no foramen tympanicum on the right side (white arrow) adjacent to the external auditory canal (asterisk).

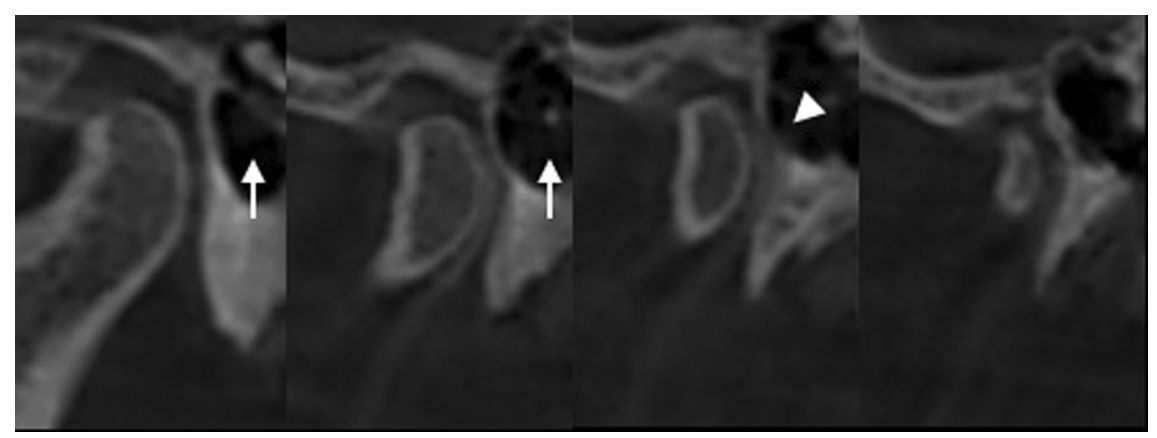

Figure 3. A cone beam computed tomography scan (saggital plane) showing the foramen tympanicum (arrowhead) on the anterior aspect of the right external auditory meatus (thin arrow)

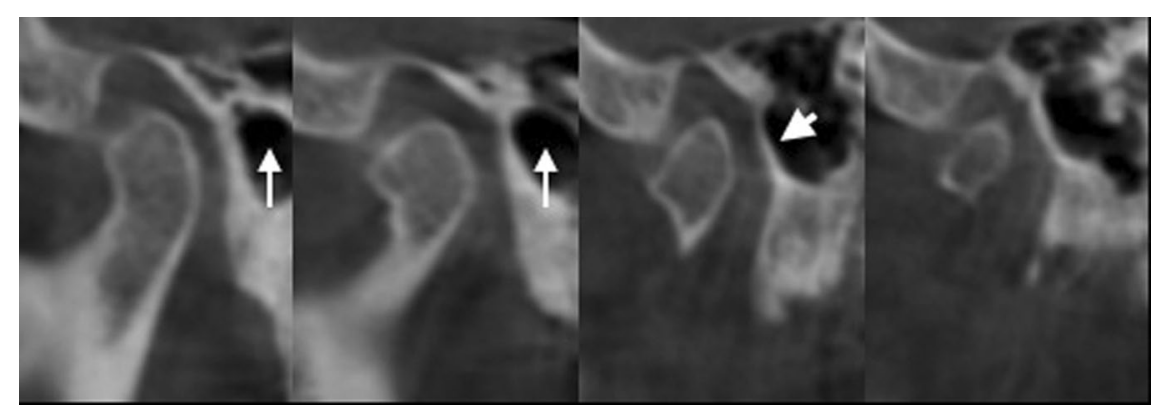

Figure 4. A cone beam computed tomography scan (saggital plane): there is no foramen tympanicum (white thick arrow) on the anterior aspect of the right external auditory meatus (thin arrow). 
This lamina extends to the midline of the tube until it reaches the first pharyngeal pouch. Ossification of this structure develops from four centres around the mesenchyme and forms primordial tympanic ring. Bony prominences of this ring fuse at the age of 1 year, growing towards each other until they join. This fusion forms a foramen at the inferior of the ear canal, the FT. Normally, the foramen becomes smaller and completely closes throughout growth, and is not present in adults. Thus, FT is not a true foramen; it is an osseous defect or dehiscence [18].

The FT can form a connection between infratemporal fossa and EAC. It is important because it may provide a route for spreading of tumours and infection. Also FT may cause TMJ herniation into the EAC and salivary secretion flow into the EAC during mastication. The aim of this study is to determine the prevalence, location and size of FT on cone-beam computed tomography (CBCT) images in a Turkish sub-population.

\section{MATERIALS AND METHODS}

In this study, randomly chosen $200 \mathrm{CBCT}$ images (400 ears), taken for any reason at the Department of Maxillofacial Radiology, Ondokuz Mayıs University, were retrospectively examined. The protocol was approved by Ondokuz Mayıs University Clinical Research Ethics Committee.

The images were studied with Galileos Comfort Plus Cone Beam Computed Tomography Unit (Sirona Dental Systems Inc., Bensheim, Germany). GALILEOS (Sirona Dental Systems, Bensheim, Germany), operating at $98 \mathrm{kVp}, 15-30 \mathrm{~mA}$. System has $15 \mathrm{~mm} \times$ $15 \mathrm{~mm}$ field of view. Real-time reconstruction was performed using the SIRONA Sidexis XG image viewer. Obtained images were $0.25 \mathrm{~mm}^{3}$ voxel size and consisted of 12 bit grayscale images. Flat panel colored active matrix TFT images were evaluated on the medical display. (Nio Colour 3 MP, Barco, Kortrijk, Belgium).

The images of the patients with bone disease, skeletal asymmetries or trauma, congenital disorders, pathological disorders of the temporal bone and mandible were excluded from the study. In addition, low-quality images, such as containing scattering were excluded.

Sagittal, axial, and cross-sectional CBCT images of 200 patients were retrospectively evaluated to determine the size and position of the FT. Distinguishing characteristics of size and location (unilateral and bilateral) of the FT were noted and its prevalence calculated twice by two observers. The observers examined all images twice promptly at different times of a week. For measurements, we used "distance tool bar" feature of image analysis programme (SIDEXIS XG 2.56, Sirona Dental Inc., Bensheim, Germany).

The study was carried out according to the principles described in the Declaration of Helsinki. Images were randomly selected, regardless of age and sex. In this retrospective study using randomly chosen 200 CBCT images, there is only 10 patient $C B C T$ image under 18 age. So statistical evaluation could not be performed especially for children.

\section{RESULTS}

Inter-observer and intra-observer variability was estimated by weighted Kappa statistics using SPSS 15.0 programme. It showed high level of agreement both in terms of intra-observer variability and between researcher 1 and researcher 2 . In this study, $116(58 \%)$ female and $84(42 \%)$ male patients were observed. FT was determined in 23 (11.5\%) of 200 patients (they had FT at least on one side of the head). This was bilateral in $5(2.5 \%)$ patients.

We determined $8(4 \%)$ FT on the right side and $15(7.5 \%)$ FT on the left side. McNemar test showed that FT was found to be significantly higher on left side $(p<0.05)$.

Fisher's exact test showed that prevalence of the FT was significintly higher in females $(8 \%)$ than in males $(3.5 \%)$. We found relationship between sex and FT $(p<0.05)$.

On the right side $\mathrm{FT}$ was observed in $2.5 \%$ of females and $1.5 \%$ of males. Chi-square test showed no statictical relationship between sex and right side FT. On the left side FT was observed in $5.25 \%$ of females and $2.25 \%$ of males. Chi-square test showed that prevalence of the FT on the left side was higher in females $(p<0.05)$.

Mean axial diameter was $1.13 \mathrm{~mm}$ (range 0.23$-4.43 \mathrm{~mm}$ ), and mean sagittal diameter was $1.44 \mathrm{~mm}$ (range $0.22-3.99 \mathrm{~mm}$ ). On the right side, mean diameter was $1.32 \mathrm{~mm}$ (range $0.23-2.52 \mathrm{~mm}$ ) in the axial plane, and mean diameter was $1.33 \mathrm{~mm}$ (range $0.42-3.77 \mathrm{~mm}$ ) in the sagittal plane. On the left side, mean diameter was $1.04 \mathrm{~mm}$ (range $0.22-3.99 \mathrm{~mm}$ ) in the axial plane, and mean diameter was $1.33 \mathrm{~mm}$ (range $0.42-3.77 \mathrm{~mm}$ ) in the sagittal plane. No correlation between location and FT diameter was found by one-way analysis of variance ( $p>0.05$ ). 
In females, on the right side mean diameter was $1.33 \mathrm{~mm}$ in saggittal plane, and mean diameter was $1.24 \mathrm{~mm}$ in axial plane; on the left side mean diameter was $1.47 \mathrm{~mm}$ in saggittal plane, and mean diameter was $0.92 \mathrm{~mm}$ in axial plane. In males, on the right side mean diameter was $1.33 \mathrm{~mm}$ in saggittal plane, and mean diameter was $1.48 \mathrm{~mm}$ in axial plane; on the left side mean diameter was $1.39 \mathrm{~mm}$ in saggittal plane, and mean diameter was $1.24 \mathrm{~mm}$ in axial plane. Measurements were evaluated using one-way analysis of variance. Mean sizes did not differ significantly by sex but were found to be greater in axial plane on the left side in males ( $p>0.05)$.

\section{DISCUSSION}

Cone beam computed tomography imaging is an effective 3-dimensional diagnostic imaging technology with a smaller radiation field than multidetector computed tomography (MDCT). CBCT has a better spatial resolution than MDCT and also is easier to perform technically. Dalchow et al. [9] showed in their temporal bone study that small pathological processes can be well analysed and anatomical process can be well visualised with $C B C T$. Also, these researchers compared $C B C T$ scans of 25 patients with conductive hearing loss and proved that CBCT could be used in the diagnosis of temporal bone pathologies and identification of anatomical landmarks [8].

Foramen tympanicum is a developmental defect located at antero-inferior aspect of EAC. Before 5 years of age, it gradually narrows and completely closes, but sometimes it fails to close. Persistent tympanic bone dehiscence arises at the region of fusion of the two prominences $[4,21]$. In a sub-population ranging from $4.6 \%$ to $22.7 \%$ FT may persist throughout life $[2,16,20]$.

In this study, FT was present at least on one side of the head in $11.5 \%$ of the 200 patients. Akbulut et al. [2] detected FT in $22.7 \%$ of patients on CBCT images; Lacout et al. [16] identified FT in $4.6 \%$ of patients on high-resolution spiral CT images. Tozoğlu et al. [20] observed FT frequency of $17.9 \%$ on CBCT images. Afghari et al. [1] reported FT frequency of $6.9 \%$ on $\mathrm{CBCT}$ images. CBCT has better spatial resolution and much better contrast resolution compared with conventional CT. These technical advantages of $\mathrm{CBCT}$ may explain differences in $\mathrm{FT}$ ranges between $\mathrm{CT}$ and $C B C T$ studies. Thus, $C B C T$ may be more effective than MDCT in radiological assessment of FT.
Akbulut et al. [2] found frequency of FT on the right side (17.8\%) was significantly different from the left side $(14.05 \%)$ ( $p<0.05)$. Tozoğlu et al. [20] revealed frequency of FT significantly higher on the right side $(15.5 \%)$ than on the left side $(7.2 \%)(p<0.05)$. Akbulut et al. [2] reported unilateral presence of FT in $59.5 \%$ and bilateral in $40.5 \%$ of patients with $\mathrm{FT}$. Tozoğlu et al. [20] observed it was unilateral in $11.6 \%$ and bilateral in $6.3 \%$ of patients. In this study, we determined FT on the right side in $4 \%$ of patients and FT on the left side in $7.5 \%$ of patients $(p<0.05)$. This was bilateral in $2.5 \%$ of patients. The relationship between the side and FT can be responsible for mastication habits and genetic factors of study populations.

In literature, researchers reported female predominance of FT [5-7, 12, 14, 16, 19, 22]. Akbulut et al. [2] found no difference between sexes ( $p>0.05$ ), but bilateral presence of FT was seen more frequently in women $(p<0.05)$. Lacout et al. [16] reported female predominance $(p<0.05)$. Afghari et al. [1] found FT prevalence was higher in females $(p<0.05)$. We found a relationship between sex and persistent FT; consistently with previous studies, female predominance was determined. This female predominance of FT might have been based on growth and development differences of osseous structures between genders. Studies performed on the temporal bones taken from different human populations described effects of sex on growth and development of temporal bone $[11,14]$.

In this study, we found mean diameter was $1.32 \mathrm{~mm}$ (range $0.23-2.52 \mathrm{~mm}$ ) on the right side in the axial plane and $1.33 \mathrm{~mm}$ (range $0.42-3.77 \mathrm{~mm}$ ) on the sagittal plane. On the left side, mean diameter was reported $1.04 \mathrm{~mm}$ (range $0.22-3.99 \mathrm{~mm}$ ) on the axial plane and $1.33 \mathrm{~mm}$ (range $0.42-3.77 \mathrm{~mm}$ ) on the sagittal plane. Researchers estimated that shape of the foramina is oval because FT's dimensions in axial plane are slightly bigger than in sagittal plane in their studies [2, 16, 22]. We investigated that shape of the foramina was oval, like in previous studies; mean sagittal size of FT was bigger than axial size of FT. But unlike the previous studies, mean sagittal dimension of FT was very close to mean axial dimension of FT.

Pathologies associated with FT were reported in the literature. An unhealthy condition associated with $\mathrm{FT}$ is soft tissue migration from TMJ to EAC and this situation can lead to TMJ pain and dysfunction $[4,12]$. The origin of this migration is uncertain, but 
reported as a complication of TMJ arthritis and external otitis $[13,15,22]$. FT may facilitate ear injury during TMJ arthroscopy. Endoscope may penetrate into the EAC accidently owing to FT [12]. Other reported pathologies are salivary-gland fistulas and synovial TMJ fistulas [13, 19, 22]. FT forms an anatomic way between the EAC and the infratemporal fossa [22]. Because of this, infection or tumour may spread into the infratemporal fossa from the EAC or into the EAC from the infratemporal fossa $[7,9,10]$.

\section{CONCLUSIONS}

In conclusion, the FT is an uncommon developmental defect and also very well demonstrated on CBCT. CBCT imaging system may be preferred to CT imaging system to examine these anatomical variations. Clinicians and radiologists should be aware of the possible presence of this developmental defect because it may affect the diagnosis, treatment plan and prognosis. CBCT may be preferred imaging modality for evaluation of anatomical structures in the near future.

\section{REFERENCES}

1. Afghari $P$, Ghaffari $R$, Sohilipour $S$. Anatomical assessment of foramen tympanicum using cone beam computed tomography images. Dental Hypotheses. 2016; 7(3): 107, doi: 10.4103/2155-8213.190486.

2. Akbulut N, Kursun S, Aksoy S, et al. Evaluation of foramen tympanicum using cone-beam computed tomography in orthodontic malocclusions. J Craniofac Surg. 2014; 25(2): e105-e109, doi: 10.1097/SCS.0000000000000440, indexed in Pubmed: 24469373.

3. Akcam T, Hidir Y, llica AT, et al. Temporomandibular joint herniation into the external ear canal through foramen of Huschke. Auris Nasus Larynx. 2011; 38(5): 646-649, doi: 10.1016/j.anl.2011.01.004, indexed in Pubmed: 21316883.

4. Anson J, Donaldson JA. Surgical anatomy of the temporal one. 3rd ed. WB Saunders. Philadelphia. 1981: 122-123.

5. Applebaum EL, Berg LF, Kumar A, et al. Otologic complications following temporomandibular joint arthroscopy. Ann Otol Rhinol Laryngol. 1988; 97(6 Pt 1): 675-679, doi: 10.1177/000348948809700618, indexed in Pubmed: 3202572.

6. Cecire AA, Austin BW, Ng PK. Polyp of the external ear canal arising from the temporomandibular joint: a case report. J Otolaryngol. 1991; 20(3): 168-170, indexed in Pubmed: 1870164.

7. Chilla R. [Otosialorrhoea - a rare case of a spontaneous salivary fistula of the external auditory canal]. HNO. 2002; 50(10): 943-945, doi: 10.1007/s00106-001-0581-9, indexed in Pubmed: 12376910.

8. Dalchow CV, Weber AL, Bien S, et al. Value of digital volume tomography in patients with conductive hear- ing loss. Eur Arch Otorhinolaryngol. 2006; 263(2): 92-99, doi: 10.1007/s00405-005-0995-1, indexed in Pubmed: 16163510.

9. Dalchow CV, Weber AL, Yanagihara N, et al. Digital volume tomography: radiologic examinations of the temporal bone. Am J Roentgenol. 2006; 186(2): 416-423, doi: 10.2214/AJR.04.1353, indexed in Pubmed: 16423947.

10. Dingle AF. Fistula between the external auditory canal and the temporomandibular joint: a rare complication of otitis externa. J Laryngol Otol. 1992; 106(11): 994-995, doi: 10.1017/s0022215100121565, indexed in Pubmed: 1479280.

11. Gonzalez PN, Bernal V, Perez SI. Analysis of sexual dimorphism of craniofacial traits using geometric morphometric techniques. Int J Osteoarchaeol. 2011; 21(1): 82-91, doi: 10.1002/oa.1109.

12. Hawke M, Kwok P, Mehta M, et al. Bilateral spontaneous temporomandibular joint herniation into the external auditory canal. J Otolaryngol. 1987; 16(6): 387-389, indexed in Pubmed: 3694748.

13. Hawke M, Kwok P, Shankar L, et al. Spontaneous temporomandibular joint fistula into the external auditory canal. J Otolaryngol. 1988; 17(1): 29-31, indexed in Pubmed: 3343717.

14. Heffez L, Anderson D, Mafee M. Developmental defects of the tympanic plate: case reports and review of the literature. J Oral Maxillofac Surg. 1989; 47(12): 1336-1340, doi: 10.1016/0278-2391(89)90738-6, indexed in Pubmed: 2685214.

15. Kozerska M, Skrzat J, Szczepanek A. Application of the temporal bone for sex determination from the skeletal remains. Folia Med Cracov. 2015; 55(2): 33-39, indexed in Pubmed: 26839241.

16. Lacout A, Marsot-Dupuch K, Smoker WRK, et al. Foramen tympanicum, or foramen of Huschke: pathologic cases and anatomic CT study. Am J Neuroradiol. 2005; 26(6): 1317-1323, indexed in Pubmed: 15956489.

17. Mao JJ, Nah HD. Growth and development: hereditary and mechanical modulations. Am J Orthod Dentofacial Orthop. 2004; 125(6): 676-689, doi: 10.1016/ /S0889540604001908, indexed in Pubmed: 15179392.

18. Prowse SJ, Kelly G, Agada F. Temporomandibular joint herniation and the foramen of Huschke: an unusual external auditory canal mass. J Laryngol Otol. 2011; 125(12): 1279-1281, doi: 10.1017/S0022215111002295, indexed in Pubmed: 21910955.

19. Sharma PD, Dawkins RS. Patent foramen of Huschke and spontaneous salivary fistula. J Laryngol Otol. 1984; 98(1): 83-85, doi: 10.1017/s0022215100146225, indexed in Pubmed: 6693808.

20. Tozoglu U, Caglayan F, Harorli A. Foramen tympanicum or foramen of Huschke: anatomical cone beam CT study. Dentomaxillofac Radiol. 2012; 41(4): 294-297, doi: 10.1259/dmfr/62359484, indexed in Pubmed: 22517996.

21. Wang RG, Bingham $B$, Hawke $M$, et al. Persistence of the foramen of Huschke in the adult: an osteological study. J Otolaryngol. 1991; 20(4): 251-254, indexed in Pubmed: 1920577.

22. Weissman JL, Hirsch BE, Chan K, et al. Dehiscent temporomandibular joint. Radiology. 1991; 180(1): 211-213, doi: 10.1148/radiology.180.1.2052697. 